\title{
Co-existence of homogeneous flow and localized plastic deformation in tension of amorphous Ni-P films on ductile substrate
}

\author{
X.L. Lu, Y. Li*, L. Lu* \\ Shenyang National Laboratory for Materials Science, Institute of Metal Research, Chinese \\ Academy of Sciences, 72 Wenhua Road, Shenyang, 110016, P.R. China \\ *Corresponding authors.E-mail addresses:liyi@imr.ac.cn,llu@imr.ac.cn
}

\begin{abstract}
The room temperature mechanical behavior of amorphous Ni-P thin films deposited on Ni substrate under tension was systematically investigated. Due to the effect of substrate confinement, unexpected homogeneous plastic flow occurred in the film simultaneously with cracking or shear banding, which co-contributed to the plastic deformation. The film thickness gradually reduced with increasing tensile strain and the maximum reduction increased up to $69 \%$ in $2.6 \mu$ m-thick film. Such a severe plastic deformation leads to significant structure change in the film where free volume annihilation dominates, evidently by almost $100 \%$ reduction in the total relaxation enthalpy in the deformed film, accompanied by the densification and hardening. The stress required for shear band and crack propagation in Ni-P film was analyzed on the basis of Griffith's criterion. A deformation map is proposed to account for co-existence of homogeneous flow and localized plastic deformation (shear banding or cracking), as well as the transition of deformation modes.
\end{abstract}

Keywords: Amorphous film; Mechanical property; homogeneous flow; Deformation mode 


\section{Introduction}

Metallic glasses (MGs) have proven to be a group of promising materials for their excellent mechanical and chemical properties, such as high strength and hardness as well as high corrosion resistance that provide great potential for various applications in industry [1-3]. However, plastic deformation of large-sized MGs is highly localized into shear band under uniaxial stress, resulting in a limited plastic strain and catastrophical failure at room temperature [4,5]. It is thus believed that MG sample only deforms elastically in the rest of sample volume without shear band $[1,6]$. On the other hand, deformation of MG is homogeneous via viscous flow (also characterized as homogeneous flow) at high temperatures near or above the glass transition and low strain rates [1,7]. The deformation map for MGs, constructed by Spaepen [7] on the basis of free volume theory and reviewed by Schuh et al. [1], indicates a strict separation between the regimes of inhomogeneous (shear localization) and homogeneous deformation. This implies that homogeneous flow would not occur at room temperature.

Be that as it may, numerous studies on nano-sized thin films or pillars have reported an existence of a transition of deformation mode from localized to non-localized (e.g. homogeneous flow) at room temperature after critical reduction in specimen size [8-11]. Apparent differences in experimental details (such as the compositions, specimen taper geometry, and surface modification induced by FIB), created intense arguments and contradicting conclusions on whether there exists the transition of deformation mode or not, as well as the critical sample size of the transition [12].

Furthermore, many previous studies have shown that shear band and homogeneous deformation were both observed in compression of nano-sized pillar. For instance, plastic flow was observed by Shan et al. [13], during in situ TEM compression tests performed on a Zr-based MG nanopillar with $300 \mathrm{~nm}$ in diameter, contributing to the widening and shortening of the pillar. Nevertheless, localized 
deformation in the form of a shear band was also observed in a later stage of the plastic deformation. Bharathula et al. [14] presented a mixture of localized and non-localized flow that contributed to the plastic deformation of specimens with diameter of less than $300 \mathrm{~nm}$. Cu-based MG pillars with tip diameters ranging from 93 to $645 \mathrm{~nm}$ under compression, reported by Chen et al. $[15,16]$, show intermittent plastic flow accommodated by inhomogeneous shear banding. Meanwhile, by nanoindenting cold rolled MG ribbon, Atzmon et al. [17] also demonstrated stable homogeneous flow taking place at pre-existing shear bands. Such technical literature not only indicate an apparent difficulty to completely prevent shear band formation but also identify the simultaneous coexistence and contribution of the two mechanisms of shear banding and homogenous flow to the plastic deformation within MGs.

Several studies have revealed recently that constraining MG films by plastic substrate could suppress the strain localization and early rupture, thereby enhancing its plasticity remarkably [18,19]. Bending [20] and nanoindentation [21] experiments on the glassy films have shown that amorphous coating possesses plastic deformation ability which can improve the fatigue life of crystalline metallic substrates [22]. Furthermore, bending tests conducted by Cao et al. [20,23] and Ma et al. [24,25] investigate the transition of deformation mode from highly localized to non-localized with film thickness of $\sim 250 \mathrm{~nm}$. These observations raise interesting questions: "Is it possible to observe homogeneous plastic deformation in macro-sized MG film during tensile tests at room temperature?" "What exactly is the transition of deformation mode like, suddenly saltation or gradually change?"

With such queries in mind, the study in this paper primarily focuses on the tensile behavior of Ni-P amorphous films with different film thicknesses (from 2.6 to $26.4 \mu \mathrm{m})$ deposited on coarse grained (CG) Ni substrate. Continual and gradual reduction of film thickness with increasing tensile true strain was revealed experimentally. Both localized (shear band or crack) and non-localized (homogeneous flow) deformation were detected in tension of Ni-P amorphous films simultaneously, 
which are implied to have co-contributed to plastic deformation. The mechanism of such homogeneous flow is discussed on the basis of the substrate confinement and film thickness effect. The deformation map and the transition of deformation modes in Ni-P amorphous film are analyzed by analogy with conditions for homogenous flow, shear band and crack propagation.

\section{Experimental}

\subsection{Sample Preparation}

High purity coarse grained (CG) Ni with $\{200\}$ out-of-plane texture was used as the substrate. A strong preferential orientation was revealed in the CG Ni substrate by XRD analysis. The CG Ni were grinded and mechanically polished carefully and then activated by electrolysis. After the surface treatment, the samples were immersed into a hypophosphate bath for Ni-P amorphous film chemical deposition. The chemical compositions of the solution are as follows: $20 \mathrm{~g} / 1$ nickel sulfate, $30 \mathrm{~g} / 1$ sodium hypophosphite, $30 \mathrm{~g} / 1$ sodium acetate, $12.5 \mathrm{ml} / 1$ lactic acid, and $1 \mathrm{mg} / 1$ lead acetate. The solution was maintained at $\mathrm{pH}$ value of $4.5 \sim 5.0$ and temperature of $85 \pm 2{ }^{\circ} \mathrm{C}$. Ni-P amorphous films with different thickness were synthesized at time durations between 30 min and 2.5 hours. Dog bone-shaped flat tensile samples with a gauge length of 5 $\mathrm{mm}$ and a width of $2 \mathrm{~mm}$ were cut from the as-deposited sample using an electric spark machine and then mechanically grinded and polished to a final thickness of 1.5 $\mathrm{mm}$.

\subsection{Tensile Tests}

Uniaxial tensile tests were performed in an Instron 5848 microtester at a strain rate of $5 \times 10^{-3} \mathrm{~s}^{-1}$ at room temperature. A contactless MTS LX300 laser extensometer (Eden Prairie, MN, USA) was used to calibrate and measure the sample strain upon loading. During the tensile testing, a non-contact optical 3D deformation measuring system (ARAMIS, GOMmbH, Germany) was coupled with the test machine to measure the local strain distribution on the amorphous film surface. The sample surface was sprayed with stochastic white and black dots pattern for the system to 
recognize the position and shape before tension. The ARAMIS system consists of two high-resolution CCD cameras which can record hundreds of images of the specimen at every specified time interval in various load stages during tensile tests. The system can divide every image into many small squares (called facets) according the dots pattern and calculate the local displacement and plastic strain of the facets by computing the change of facets position. The local accuracy of strain deformation is up to $0.01 \%$ [26]. An external data interface was also connected with the test machine which can transfer the force data into the system. After successful computation by ARAMIS, the local plastic strain distribution of the film surface can be acquired in various engineering stress or strain stages.

\subsection{Post inspection}

After tensile tests, the sample surfaces were first examined in an FEI Nova NanoSEM 430 field emission gun scanning electron microscope (SEM) with secondary electron imagining using an ETD detector. Then the samples were coated by a protecting $\mathrm{Ni}$-coating, and cut along the tensile direction to observe the film deformation from longitudinal section. Cross-sectional microstructures of the samples, before and after tensile deformation, were examined by SEM with back scattering electron (BSE) imaging using a VCD detector. X-ray diffraction (XRD) measurements were carried out on the plane surface of the as deposited samples using a Rigaku DMAX/2400 X-ray diffractometer with $\mathrm{Cu} \mathrm{K}_{\alpha}$ radiation at grazing incidence angle of $\alpha_{0}=4^{\circ}$. Chemical compositions of all the test samples were determined by energy dispersive X-ray spectroscopy (EDX) with Oxford INCA X-act fixed on SEM 430. A Tecnai $G^{2}$ F20 transmission electron microscope (TEM) operated at $200 \mathrm{kV}$ was used to character the structure of Ni-P amorphous film.

Nano-indentation was carried out by using a triboindenter (Agilent Technologies, Nano Indenter G200, USA). A maximum displacement of $300 \mathrm{~nm}$ and $10 \mathrm{~s}$ holding time (at the peak hold load) were applied. The as-deposited and deformed films were cut off from the substrates carefully by mechanical grinding and polishing for thermal 
tests. All of the tested samples were examined by chemical composition to verify successful removal from the substrate.

Differential scanning calorimetry (DSC) analysis was carried out using a Flash DSC 1 STAR $^{\mathrm{e}}$ system (METTLER TOLEDO) which is suitable for micro-scale samples at a heating rate of $50 \mathrm{Ks}^{-1}$ with the flow of argon. The size of the specimen (after being cut off from the substrate) was about $50 * 70 * 14 \mu \mathrm{m}^{3}$ and resultant mass calculated was $\sim 380 \mathrm{ng}$. A second run under the identical condition was utilized for determining the base line after each measurement.

\section{Results}

\subsection{Microstructure of the samples}

Fig. 1 collectively shows the cross sectional SEM images of Ni-P amorphous films with various thickness ranging from $26.4 \mu \mathrm{m}$ to $2.6 \mu \mathrm{m}$, deposited on the coarse grained (CG) Ni substrate. The grain size of the Ni substrate had a wide distribution ranging from 1 to $30 \mu \mathrm{m}$. As seen in Figs. 1(a-d), the interface between film and substrate can be clearly distinguished as being sharp, straight and clean for all the samples, signifying that the films were well-bonded to the Ni substrate. The XRD results (Fig. 2a) of the deposition surfaces show typical "broad peaks", indicating the amorphicity of Ni-P films. No lattice fringes and only a homogeneous maze contrast were found by HRTEM (Fig. 2b), while the inset shows a selected area electron diffraction (SAED) pattern without crystalline spots and rings, further confirming the monolithic amorphous phase. No nanocrystalline was observed both in the thick and thin films. The EDX analysis shows that the P content of the Ni-P amorphous films was in the range of 9.2 11.3 wt.\%, as listed in Table 1 , which is well within the typical range of $8-14$ wt. \% for the composition of the amorphous film reported previously [27-29]. There were some horizontal bandings (i.e. striations) observed in the two thicker films (in $26.4 \mu \mathrm{m} \& 14.3 \mu \mathrm{m}$-thick films). These striations are characteristic of periodic variations of the phosphorus content, rather than alternate lamellae of different phases or interfaces [27,30]. The phosphorus content varied 
slightly from $9.8 \%$ to $10.5 \%$ in the depth of the $26.4 \mu \mathrm{m}$ film by EDX analysis in this study which is still in the range of amorphous structure. It was reported that pulse plating can eliminate the banded structure in the film but has no significant effect on the mechanical properties of the deposits [31].

\subsection{Tensile properties}

Typical engineering tensile curves of Ni-P films with different thicknesses on the substrate are shown in Fig. 3. For comparison, tensile behaviors of CG Ni substrate and free-standing $\mathrm{Ni}_{80} \mathrm{P}_{20}$ ribbon prepared by melt-spinning [32] are also included in Fig. 3. Apparently, the ribbon showed high strength but almost no plasticity, thereby having a tensile elongation of no more than $2 \%$. The sample with $14.3 \mu \mathrm{m}$-thick Ni-P film coating exhibited a much more enhanced tensile strength (yield strength at $0.2 \%$ strain offset $\sigma_{y}=310 \mathrm{MPa}$, ultimate tensile strength $\sigma_{u t s}=430 \mathrm{MPa}$ ), compared to those for the CG Ni sample $\left(\sigma_{y}=276 \mathrm{MPa}, \sigma_{u t s}=402 \mathrm{MPa}\right)$.

Fig. 4 reveals the macro morphologies of the samples after tension. The overall lengths of the four tensile samples were almost the same. Visual observation could not identify any distinct difference with ductility, which is consistent with engineering tensile curves shown in Fig. 3. Large cracks vertical to the loading direction were observed in $14.3 \mu \mathrm{m}$-thick Ni-P film. However, with decreasing in the film thickness, the film surfaces became smoother with only mini cracks.

The true strain $\left(\varepsilon_{T}\right)$ of the tensile sample at different positions after failure (Fig. 5) can be estimated from the cross-sectional area $(S)$ reduction by $\varepsilon_{T}=\ln \left(S_{0} / S\right)$, where $S_{0}$ is the original cross section area in gauge before tension. The cross-sectional area can be calculated by $S=H W$, where $H$ and $W$ represent the thickness and width of the tensile sample within gauge after tension, respectively, which can be measured as shown in Figs. 5a \& b at corresponding positions. The true strain increased with the distance from the arc ending, as plotted in Fig. 5c. Since the ductility of the sample is mainly controlled by the substrate, the true strain for the five samples show almost the same tendency of increasing with the distance from the arc ending, independent on the film thickness. 


\subsection{Surface morphology after tension and fracture mechanism}

Snapshots of local plastic strain distributions on the surface during tensile test, extracted from the ARAMIS recorder, are shown in Fig. 6. Fig. 6a depicts that the surface strain was localized in the horizontal regions (channel cracks) in the early stage of tension (engineering strain $\varepsilon=5 \%$ ); however when the engineering strain increased to $25 \%$, the local strain (Fig. 6b) in the surface was even more uniform, similar as the substrate deformed without film on the surface (Fig. 6c). Comparison between Figs. $6 \mathrm{a}$ and $6 \mathrm{~b}$ easily interprets the increase in the strain of the area between the cracks, which characterizes that the film segment (the film between two adjacent cracks) deformed concurrently with the substrate deformation during the tensile test. The movie created by ARAMIS during tension can be found in Supplemental Material.

A magnified SEM image of the film surface in Fig. 7a displays large channel cracks that propagated vertically through the tensile direction on the $14.3 \mu \mathrm{m}$-thick Ni-P surface, after tension. A few cracks induced by shear banding with angle of $\sim 45^{\circ}$ to depth direction were observed in the thin films, as indicated by dashed circles in Fig.7b \& 7c. Shear bands were also observed on the surface of film segments in the $6.1 \mu \mathrm{m}$ and $2.6 \mu \mathrm{m}$-thick films. With decreasing in film thickness, the crack width and film segments spacing also decreased at similar tensile true strain, while the angle between cracks and tensile direction gradually reduced from $90^{\circ}$ to $45^{\circ}$. Especially within $2.6 \mu \mathrm{m}$-thick film (Fig. 7d), the cracks turned into discontinuous, dense and tiny "zigzag" form which are similar to the surface of nanoscale $\mathrm{Cu}$ film on polymer substrate after 30\% tensile strain, reported by Xiang et al. [33], implies that MG films well bonded to a ductile substrate can also achieve a large elongation like crystalline films.

On the surface of $14.3 \mu \mathrm{m}$-thick film (Fig. 7a) after failure, the fracture surface of channel crack is vertical to the surface (cleavage); however with decreasing in film thickness, the fracture surface gradually inclined to the surface (shear band). The fracture characteristics can also be observed from the longitude-sectional images. By 
checking fracture in longitude sectional images, fracture type associated with 14.3 $\mu$ m-thick film ruptured by cleavage (e.g. Fig. 8 e \& 8 f); while in $2.6 \mu$ m-thick film, it turned out to be shearing, as indicated by dashed circles in Fig. $8 \mathrm{~h}$. It is obvious that the failure mode gradually transited from cleavage to shear band with decreasing in film thickness. Mixed fracture types of both shear and cleavage can be observed sometimes in $14.3 \mu \mathrm{m}$-thick Ni-P film as well. The critical thickness of the transition is estimated to be about 3-4 $\mu \mathrm{m}$.

\subsection{Film thickness reduction}

To reveal the variation of film thickness in tension, longitude-sectional of Ni-P films on CG Ni substrate after failure were observed at different tensile true strains. As shown in Fig. 8, for the $26.4 \mu$ m-thick Ni-P film, the film thickness is almost unchanged with the increasing tensile true strain even up to $86 \%$. However, for the $14.3 \mu \mathrm{m}$-thick Ni-P film, the film thickness reduced from initial thickness of $14.3 \mu \mathrm{m}$ without strain $\left(\varepsilon_{T}=0 \%\right)$ to $11.4 \mu \mathrm{m}$ in the middle $\left(\varepsilon_{T}=16 \%\right)$, and then to $8.6 \mu \mathrm{m}$ at the necking zone ( $\varepsilon_{T}=96 \%$ ); while for $2.6 \mu \mathrm{m}$ film, the film thickness reduced from initial thickness of $2.6 \mu \mathrm{m}$ without strain $\left(\varepsilon_{T}=0 \%\right)$ to $1.5 \mu \mathrm{m}$ in the middle $\left(\varepsilon_{T}=32 \%\right)$, and then to $0.8 \mu \mathrm{m}$ at the necking zone $\left(\varepsilon_{T}=128 \%\right)$. Additionally, local thinning in crack tip can also be observed in $2.6 \mu$ m-thick film around the necking region. Further observation reveals that the grains in the $\mathrm{CG} \mathrm{Ni}$ substrate refined as the strain increased, and predominately the grains beneath the crack area were finer than the surrounding grains at close proximity to the crack area.

The film thickness reduction $\left(T_{r}=\Delta h / h_{0}\right.$, where $h_{0}$ is the as-deposited film thickness before tension, $\Delta h$ is the reduced film thickness) are plotted as a function of tensile true strain $\left(\varepsilon_{T}\right)$ in Fig. 9. For the $14.3 \mu \mathrm{m}$ and $2.6 \mu \mathrm{m}$ - thick Ni-P film, the film thickness gradually reduced with the increasing tensile true strain, while the thickness reduction increased approximately linearly with the increase of the true strain before necking. The largest thickness reduction could be as high as $69 \%$ in the $2.6 \mu \mathrm{m}$ film. Furthermore, the smaller the film thickness, the larger the thickness reduction will be at the same true strain. 


\subsection{Nano-indentation hardness}

A nanoindentation test was performed on the cross section of the $14.3 \mu \mathrm{m}$ film sample at different strain levels, as shown in Fig. 10. The hardness of as-deposited film was indicated by a star, at $6.2 \pm 0.2 \mathrm{GPa}$. Whether the horizontal striations have an influence on the original hardness of the film remains to be studied in future. The hardness remained almost unchanged when the true strain is less than $50 \%$, while when the true strain reaches over than $85 \%$, the hardness gradually increased to a maximum $\sim 7 \mathrm{GPa}$, about $10 \%$ increase of its initial value.

\subsection{Free volume reduction}

Such drastic thickness reduction and plastic deformation in the MG film must imply significant change in the structure, which is associated with variation in free volume. Most common method to investigate the content of free volume in MG is to measure the enthalpy relaxation by examining the endothermic signals shown in DSC curves before the glass transition.

Flash DSC, which is capable of studying tiny sample with weigh less than $1 \mu \mathrm{g}$ due to its unique twin chip design [34], was employed to study the enthalpy relaxation of $14.3 \mu \mathrm{m}$-thick Ni-P film specimens after tensile test at various plastic strain levels. The results, as shown in Fig. 11a, expose a significant reduction in exothermic heat before the glass transition of the deformed samples compared with the as-deposited Ni-P sample. The relaxation enthalpy of the deformed samples as a function of true strain is plotted in Fig. 11b. It is clear that the relaxation enthalpy of the deformed samples decreases quickly with the increasing tensile true strain, indicating that there is a huge free volume reduction as plastic strain increases.

\section{Discussion}

Above experimental results provided distinct evidence that a gradual reduction in film thickness was observed together with shear banding or cracking with increasing tensile true strain in the Ni-P amorphous films. There co-exists localized deformation 
(shear band or crack) and non-localized deformation (homogeneous flow) which contributed to the plastic deformation of Ni-P film together.

Although the feature of thickness reduction in nano-scale thin film specimens was observed previously in rolling [35], however, this is the first time that amorphous film thickness has been reported to decrease so severely on micro-scale level during tensile test. Such severe plastic deformation in Ni-P film can only be explained as a kind of viscous-like homogeneous flow at room temperature. The present results also show that there is a gradual transition in deformation mode from cracking to shear banding, finally to the homogeneous flow with decreasing in the film thickness. For instance, almost no thickness reduction was observed beyond $26.4 \mu \mathrm{m}$-thick film and the film fractured by cracking; however, homogeneous flow induced thickness reduction and shear bands were observed in 6.1 and $2.6 \mu \mathrm{m}$-thick film, respectively.

The plastic deformation in the Ni-P films is closely related to the substrate confinement, which will be discussed in detail in section 4.1. A deformation map is proposed to explain the co-existence of homogeneous flow and localized deformation in section 4.2 and the transition of deformation modes. Finally, the analysis of the mechanical property of amorphous film in homogeneous flow will be discussed in section 4.3.

\subsection{Substrate confinement induced film elongation and thickness reduction}

It has been demonstrated that confinement by a ductile substrate is one of effective ways to improve the plastic deformation ability for brittle films under tensile tests [18,36]. For example, $\mathrm{Lu}$ et al. [37] reported that $\mathrm{Cu}$ films deposited on a ductile polymer substrate can achieve elongation over $50 \%$ before failure. When stretched, a free standing metal film usually ruptures at small strain $(\sim 2 \%)$ by forming local thinning within a narrow region. However, finite element simulations have shown that the substrate can delocalize the strain, so that metal film well bonded on a polymer substrate can elongate indefinitely but only limit by the rupture of the substrate [38,39]. Similarly, Fang et al. [40] showed that gradient nono-grained surface $\mathrm{Cu}$ layer can sustain a uniform elongation of $31 \%$ when it was confined by a coarse 
grained substrate. The extraordinary intrinsic tensile plasticity of nano-grained metals was revealed when strain localization and early necking were suppressed by gradient nano-structure. Our previous work [19] indicated that a uniform tensile ductility of $12 \%$ can be achieved in the $6 \mu \mathrm{m}$-thick Ni-P amorphous film coated on the gradient nanostructure by generating massive multiple shear bands.

MG film suffers from a similarly strain localization in shear band and exhibits macroscopically catastrophic failure under tension at room temperature. If MG film is well-bonded on a ductile substrate, the shear banding in the amorphous film will be suppressed by the substrate and the film can elongate with the substrate deformation as those confined crystalline metal films.

As pointed out before [39,41], the elastic mismatch and the interface bonding between the film and substrate are two key parameters in controlling the effectiveness of the confinement. The Young's modulus of Ni and Ni-P amorphous are measured to be $\sim 200 \mathrm{GPa}$ and $150 \mathrm{GPa}$ by nano-indentation, respectively. Well matched moduli between the Ni-P film and the $\mathrm{Ni}$ substrate insure that the two sides of interface can deform cooperatively in elastic stage under tension, neither by delamination nor by buckling from the interface. The comparable modulus between the film and substrate can effectively reduce the stress concentration in the interface and the risk of debonding at the interface during tensile deformation. The film remained well bonded with the substrate without observable delamination in the interface even at very large strain (even after failure), indicating the excellent adhesion between the film and substrate (Figs. 8c, f \& i).

Plastic deformation induced grain refinement and work hardening in Ni [42] substrate beneath the film crack areas prevent the strain localization in this area of the substrate. The load was transferred from the substrate into the film segments by the strongly bonded interface. The well-bonded interface between Ni-P amorphous film and CG Ni substrate assures the film and substrate always combined together and accommodates the plastic deformation of the both sides of the interface. The film 
segments between cracks elongated with the substrate under loading and thus the film thickness continuously decreased with increasing tensile true strain.

\subsection{Film thickness effect on deformation mode}

The homogeneous flow in the Ni-P amorphous film can also be attributed to the thickness effect. As shown in Fig. 9, the thinner the film, the larger the thickness reduction will be at the same true strain. The largest film thickness reduction as a function of the as-deposited film thickness is plotted in Fig. 12. It is not difficult to identify that thickness reduction decreased rapidly with increasing film thickness. When the as-deposited film thickness is above a critical value $(25-30 \mu \mathrm{m})$ in this study, the thickness reduction will decrease to $0 \%$, as indicated by the dash line, which implies that no homogeneous flow would occur in the film beyond this critical film thickness.

For a better understanding of the thickness reduction (i.e. homogeneous flow) in the $\mathrm{Ni}-\mathrm{P}$ film, it is beneficial to consider the conditions required for shear band and crack propagation. By analogy with Griffith's crack-propagation criterion, a crack or shear band can only propagate if the strain energy relief associated with the propagation is larger than the surface energy increment in forming a fresh surface [9]. The strategy proposed by Chen et al.[15] was adopted for calculating the stress required for crack or shear band propagation. This strategy considers a unit volume inside thin film $V=h^{3}$ that accommodates an individual crack or shear band, where $h$ represents the film thickness.

For uniaxial tension, the elastic strain energy density is denoted as $\mathrm{U}=\sigma^{2} / 2 E$ with $\sigma$ being the stress in the film, and $E$ being the Young's modulus of Ni-P film. We assume that only part of elastic strain energy $\left(P_{S} * U\right)$ can be transferred into the film for shear band propagation due to effect of the substrate confinement. Considering the shear band traversing the film in the thickness direction at an angle of $45^{\circ}$, the surface energy per unit area of shear band under uniaxial tension can be expressed as: 


$$
\Gamma=\sqrt{2} h \frac{\sigma^{2}}{4 E} P_{s}
$$

Similarly, if we consider the energy for crack propagation, only a proportion of elastic energy $\left(P_{c} * U\right)$ can be transferred into the film for crack propagation also due to substrate confinement. However, considering the crack traversing the film in the thickness direction at an angle of $90^{\circ}$, the energy per unit area of crack can be expressed as:

$$
\Gamma=h \frac{\sigma^{2}}{2 E} P_{c}
$$

After rewriting Eqs.(1) and (2), the stress required for shear band $\left(\sigma_{s}\right)$ or crack propagation $\left(\sigma_{c}\right)$ can be expressed as follow, respectively:

$$
\begin{gathered}
\sigma_{s}=2^{3 / 4} \sqrt{\frac{E \Gamma}{h P_{s}}} \\
\sigma_{c}=\sqrt{\frac{2 E \Gamma}{h P_{c}}}
\end{gathered}
$$

The stress required for shear band $\left(\sigma_{s}\right)$ or crack propagation $\left(\sigma_{c}\right)$ can be schematically plotted as a function of film thickness $(h)$, as shown in Fig. 13. The value of $\Gamma$ is estimated to be $0.56 \mathrm{~J} \mathrm{~m}^{-2}$ according to references [15,25]. If we can figure out the coefficient of $P_{s}$ and $P_{c}$, the curves of $\sigma-h$ for Ni-P film will be determined. $P_{s}$ and $P_{c}$ should be related to several complicated factors, such as film and substrate geometry, the volume ratio of film to substrate and Young's modulus of the material, which make it difficult to acquire a definite value. We can only estimate them from the observed critical film thickness from references and experiment.

In fact, Jang and Greer [10] have pointed out that the stress required to initiate homogeneous flow at room temperature, $\sigma_{h}$, is independent of specimen size and bounded by the yield strength $\sigma_{y}$ (lower limit) and ideal strength $\sigma_{t h}$ (upper limit). If we plotted the horizontal line of these two limit stresses in Fig. 13, there will be two 
critical film thicknesses for homogeneous flow in each $\sigma$ - $h$ curve. If we can ascertain one of these two critical values, the coefficient of $P_{s}$ or $P_{c}$ can be calculated.

When we consider the ideal strength of Ni-P glassy alloy in Fig. 13, there exists a critical film thickness $h_{f}^{*}$ for fully homogeneous deformation in $\sigma_{s}-h$ curve. When the film thickness is below this critical value, the stress required for shear band propagation is larger than ideal strength, which means the film is insensitive to any formed embryonic shear band [43]. So homogeneous deformation prevails and plastic strain becomes homogeneously distributed. Based on Eq.(3), the coefficient of $P_{s}$ can be calculated by:

$$
P_{s}=\frac{2^{3 / 2} E \Gamma}{\sigma_{t h}^{2} h_{f}^{*}}
$$

The ideal strength of Ni-P glassy alloy is $\sigma_{t h} \approx E / 30=5 \mathrm{GPa}, h_{f}^{*}$ was estimated to be about $184 \mathrm{~nm}$ according to the bending test by Ma et al. [24,25] and Cao et al. [23]. Shear bands were completely absent in tensile side of bent $\mathrm{Ni}_{60} \mathrm{Nb}_{40} \mathrm{MG}$ thin films with a thickness of less than $184 \mathrm{~nm}$. The reason why we select $\mathrm{NiNb}$ for reference is that the Young's modulus of $\mathrm{Ni}_{60} \mathrm{Nb}_{40}$ is about $149.8 \mathrm{GPa}$ measured by nanoindentation [24], which is almost equal to that of Ni-P amorphous film (150 GPa). And the geometry of substrate they put to use in the experiment is $2 \mathrm{~mm}$ wide $\times 1 \mathrm{~mm}$ thick, which is also close to that in this experiment $(2 \mathrm{~mm}$ wide $\times 1.5 \mathrm{~mm}$ thick). Therefore, $P_{S}$ is calculated to be about 5.2\% from Eq.(5) with $h_{f}^{*}=184 \mathrm{~nm}$.

Similarly, if we consider the lower limit of the stress (yield strength) for homogeneous flow, there also exists a maximum critical film thickness in $\sigma_{c^{-}} h$ curve. Based on Eq.(4), the coefficient of $P_{c}$ can be calculated by:

$$
P_{c}=\frac{2 E \Gamma}{\sigma_{y}^{2} h_{c}^{*}}
$$

The yield strength of Ni-P glassy alloy can be estimated to be $\sigma_{y} \approx H / 3 \approx 2 \mathrm{GPa}, H$ represents the hardness of the film $(6.2 \mathrm{GPa})$. The critical thickness for thickness reduction $\left(h_{c}^{*}\right)$ was observed to be $25-30 \mu \mathrm{m}$ (Fig. 12) in this experiment, which was 
considered as the maximum critical thickness for homogeneous flow in Ni-P amorphous film under tension. Thus the value of $P_{c}$ can be calculated to be about $0.168 \%$ according to Eq.(6) with $h_{c}^{*}=25 \mu \mathrm{m}$. After rewriting Eqs.(3) and (4) with the value of $P_{s}$ and $P_{c}$, the curves of $\sigma-h$ for Ni-P film can be determined as:

$$
\begin{aligned}
& \sigma_{S}=2.15 \times 10^{6} h^{-1 / 2} \\
& \sigma_{c}=1.0 \times 10^{7} h^{-1 / 2}
\end{aligned}
$$

Based on the calculation, the deformation mechanism can be delineated in the corresponding regions of stress $(\sigma)$-film thickness $(h)$ map in Fig. 13. The stress in Ni-P film increased with increasing tensile strain, and can reach a higher stress than yield strength due to substrate confinement. When the stress in film was high enough and reached the stress required for shear band or crack propagation at a given film thickness, shear banding or cracking mechanism would be triggered; when the stress is high enough and in the ranger of possible stress required for homogeneous deformation [10], the homogeneous flow would be included. According to the engineering stress-strain curve (Fig. 3), the stress in $14.3 \mu \mathrm{m}$-thick film can be estimated to be $\sim 2.8 \mathrm{GPa}$ in the uniform deformation stage, which is obviously above the yield stress of the film. This implies that homogeneous flow did take place in the film.

Fig. 13 clearly demonstrates the size-dependence of deformation modes and the relative threshold sizes of mode transition for Ni-P amorphous film in tension. Most importantly, this map reveals that the transition of the deformation mode is gradually changed via the variation of film thickness. In a certain scale of film thickness and stress, two deformation modes (i.e., shear banding plus homogeneous flow or cracking plus homogeneous flow for the samples in this work) can co-exist. With decreasing in film thickness, the mixed deformation mode gradually change from cracking plus homogeneous flow to shear banding plus homogeneous flow and eventually to fully homogeneous flow. 
The critical film thickness for crack formation $h_{c f}^{*}$ was calculated to be $4.0 \mu \mathrm{m}$ with $P_{c}=0.168 \%, \sigma_{t h}=5 \mathrm{GPa}$ in Eq.(4), which coincides with the critical film thickness of the transition in failure mode from shear banding to cleavage $(3-4 \mu \mathrm{m})$. When the film thickness is below $h_{f}^{*}=184 \mathrm{~nm}$, the whole region in the map within homogeneous flow regime, the deformation would be fully homogeneous [25]; when the film thickness increases to the scale of $184 \mathrm{~nm}$ to $4 \mu \mathrm{m}$, the deformation mode would be shear bands plus distributed homogeneous flow, as we observed in the experiment of $2.6 \mu \mathrm{m}$-thick film; when the film thickness increase to the scale of 4 $\mu \mathrm{m}$ to $25 \mu \mathrm{m}$, the deformation mode would be a mix of crack plus shear bands and distributed homogeneous flow, as we observed in the experiment of 6.1,10.5 and 14.3 $\mu \mathrm{m}$-thick film; when the film thickness beyond $25 \mu \mathrm{m}$, the deformation mode would be only cracking, as we observed in the experiment of $26.4 \mu \mathrm{m}$-thick film. The film thickness effect on deformation modes acquired from the calculation agrees well with the experimental results. We also noticed that the chemical composition in the film varied slightly with thickness. But we believe, it did not play much a role in affecting energy transfer, thus in the film thickness reduction.

The critical size for homogeneous flow is much larger than that of reported in nano sized pillar [10] or thin film [11] before. The main reason is the CG Ni substrate confinement which seems to act like energy absorber. Only a small proportion of elastic energy $(P * U)$ can be transferred into film for shear banding or crack propagation. Another reason is that the previous studies always seek for fully homogeneous deformation (no shear bands observed) and ignore distributed plastic flow (shear bands plus homogeneous flow) of which the critical size is much larger than that of fully homogeneous flow. The condition for initiating homogeneous flow in $\mathrm{MG}$ is to achieve a higher stress than $\sigma_{y}$ in the sample, which requires to suppress shear band propagation by size effect [8-10], multiaxial stress-state [44] or confinement [18-20]. This implies that MG actually is capable of homogeneous flow at room temperature when shear band is efficiently suppressed or controlled to be 
stable. This point is consistent with some previous studies. Boucharat et al. $[45,46]$ and Pauly et al. [47] had pointed out that there was plastic deformation in the amorphous "matrix" as well.

\subsection{Mechanical property of amorphous film in homogeneous flow}

Large deformation often induced softening in amorphous materials [6] when the strain is highly localized in shear bands. Free volume in the shear band increases, resulting in dilatation and softening in MG [48]. However, it has been reported that homogenous flow leads to work hardening $[10,44]$ when the stress is above a critical value at which the rate of free volume annihilation exceeds that of free volume generation. Wang et al. [44] further proven that structural ordering or free volume annihilation can be observed in homogeneous deformation area, which leads to about $10 \%$ increase in hardness.

The present experimental results also demonstrate the hardness increase and endothermic heat reduction in the deformed Ni-P film. The most interesting result shows that the hardness increase only to about $10 \%$ of its original value for the as-deposited sample (Fig. 10), which is consistent with the previous work [44]. The hardness increases in the deformed sample is on account of free volume reduction or structure ordering during the plastic deformation. It seems that the relaxation enthalpy reaches zero after $\sim 50 \%$ tensile true strain according to the DSC results (Fig. 11a). Interestingly, the hardness remained almost unchanged until the true strain in film reaches $50 \%$. This implies the hardness increase in deformed film only occurred when the free volume is reduced to a critical value.

It was also reported that structural relaxation in aging induced hardness increases by $10-14 \%$ prior to the onset of crystallization for $\mathrm{CuZr}$ and $\mathrm{FeB}$ glasses [49]. The hardness increment is similar to our experimental results, which implies that the structure change resulted by the homogeneous flow is similar to that by conventional thermal relaxation. Whether it is a coincidence or there exists an upper limit in hardness increase resulted by homogeneous flow remains to be studied in future. 


\section{Conclusions}

A comprehensive investigation into tensile behavior of the eletroless deposited Ni-P amorphous films with various thicknesses well bonded on CG Ni substrate was performed in this paper. The results clearly provided deep insights into the deformation behavior of micro-sized amorphous film on ductile substrate.

1. A co-existence of non-localized (homogeneous flow) and localized plastic deformation (shear banding or cracking) was observed in tension of Ni-P amorphous films on ductile substrate. Homogeneous flow with a gradual thickness reduction was observed in Ni-P films with increasing tensile true strain. The thinner the film, the larger the thickness reduction will be. The degree of plastic flow continues to mount up with decreasing in film thickness. The critical thickness of Ni-P amorphous film for homogeneous flow was observed to be $25-30 \mu \mathrm{m}$.

2. Due to the substrate confinement as it acts like an energy absorber, MG films can elongate with the substrate deformation and achieve a large elongation, even though localized plastic deformation (shear banding or cracking) took place in the film simultaneously.

3. A deformation map (Fig. 13) was proposed to account for the co-existence of homogeneous flow and localized deformation, and reveals the transition of deformation mode from inhomogeneous (shear banding or cracking) to homogeneous flow gradually changed via the variation of film thickness in MG film.

4. The hardness of the deformed film increased $\sim 10 \%$ after plastic deformation. The results of DSC show that the total relaxation enthalpy of deformed films decreased with increasing plastic strain, indicating that a huge free volume reduction and structure ordering occurred during the plastic deformation.

\section{Acknowledgements}

We acknowledge financial support from the National Basic Research Program of China (973 Program, 2012CB932202), the financial support from the National 
Science Foundation of China (Grant Nos. 51420105001, 51471165, 51371171 and 51471172). L.L. thanks the financial support of the "Hundreds of Talents Project" by the Chinese Academy of Sciences. The authors would like to thank Mr. S. Jin for assistance with sample preparation and Miss. F.X. Bai for the help in the DSC experiments.

\section{References}

[1] C.A. Schuh, T.C. Hufnagel, U. Ramamurty. Mechanical behavior of amorphous alloys, Acta Mater 55 (2007) 4067-4109.

[2] M. Chen. Mechanical behavior of metallic glasses: Microscopic understanding of strength and ductility. Ann Rev Mater Res, vol. 38. 2008. pp. 445-469.

[3] A. Inoue, A. Takeuchi. Recent development and application products of bulk glassy alloys, Acta Mater 59 (2011) 2243-2267.

[4] C.A. Pampillo. Flow and fracture in amorphous alloys, J Mater Sci 10 (1975) 1194-1227.

[5] J.H. Yao, J.Q. Wang, L. Lu, Y. Li. High tensile strength reliability in a bulk metallic glass, Appl Phys Lett 92 (2008) 041905.

[6] H. Bei, S. Xie, E.P. George. Softening caused by profuse shear banding in a bulk metallic glass, Phys Rev Lett 96 (2006) 105503-105504.

[7] F. Spaepen. A microscopic mechanism for steady-state inhomogeneous flow in metallic glasses, Acta Metall 25 (1977) 407-415.

[8] H. Guo, P.F. Yan, Y.B. Wang, J. Tan, Z.F. Zhang, M.L. Sui, E. Ma. Tensile ductility and necking of metallic glass, Nat Mater 6 (2007) 735-739.

[9] C.A. Volkert, A. Donohue, F. Spaepen. Effect of sample size on deformation in amorphous metals, J Appl Phys 103 (2008).

[10] D. Jang, J.R. Greer. Transition from a strong-yet-brittle to a stronger-and-ductile state by size reduction of metallic glasses, Nat Mater 9 (2010) 215-219.

[11] Q. Deng, Y. Cheng, Y. Yue, L. Zhang, Z. Zhang, X. Han, E. Ma. Uniform tensile elongation in framed submicron metallic glass specimen in the limit of suppressed shear banding, Acta Mater 59 (2011) 6511-6518.

[12] J.R. Greer, J.T.M. De Hosson. Plasticity in small-sized metallic systems: Intrinsic versus extrinsic size effect, Prog Mater Sci 56 (2011) 654-724.

[13] Z.W. Shan, J. Li, Y.Q. Cheng, A.M. Minor, S.A. Syed Asif, O.L. Warren, E. Ma. Plastic flow and failure resistance of metallic glass: Insight from in situ compression of nanopillars, Phys Rev B 77 (2008) 155419.

[14] A. Bharathula, S.-W. Lee, W.J. Wright, K.M. Flores. Compression testing of metallic glass at small length scales: Effects on deformation mode and stability, Acta Mater 58 (2010) 5789-5796.

[15] C.Q. Chen, Y.T. Pei, J.T.M. De Hosson. Effects of size on the mechanical response of metallic glasses investigated through in situ TEM bending and compression experiments, Acta Mater 58 (2010) 189-200. 
[16] C.Q. Chen, Y.T. Pei, J.T.M. De Hosson. Apparently homogeneous but intrinsically intermittent flow of taper-free metallic glass nanopillars, Scr Mater 67 (2012) 947-950.

[17] W.H. Jiang, M. Atzmon. Room-temperature flow in a metallic glass - Strain-rate dependence of shear-band behavior, Journal of Alloys and Compounds 509 (2011) 7395-7399.

[18] J.P. Chu, J.E. Greene, J.S.C. Jang, J.C. Huang, Y.-L. Shen, P.K. Liaw, Y. Yokoyama, A. Inoue, T.G. Nieh. Bendable bulk metallic glass: Effects of a thin, adhesive, strong, and ductile coating, Acta Mater 60 (2012) 3226-3238.

[19] X.L. Lu, Q.H. Lu, Y. Li, L. Lu. Gradient confinement induced uniform tensile ductility in metallic glass, Scientific Reports 3 (2013).

[20] Q.P. Cao, Y. Ma, Y. Xu, L.Y. Chen, C. Wang, Y.Y. Ruan, X.D. Wang, J.Z. Jiang. Bending behavior of electrodeposited glassy Pd-P and Pd-Ni-P thin films, Scr Mater 68 (2013) 455-458.

[21] Y.F. Shen, W.N. Liu, X. Sun, W.Y. Xue, Y.D. Wang, L. Zuo, P.K. Liaw. Plastic deformation in an amorphous Ni-P coating, Metallurgical and Materials Transactions A 43 (2012) 1610-1620.

[22] H.L. Jia, F.X. Liu, Z.N. An, W.D. Li, G.Y. Wang, J.P. Chu, J.S.C. Jang, Y.F. Gao, P.K. Liaw. Thin-film metallic glasses for substrate fatigue-property improvements, Thin Solid Films 561 (2014) 2-27.

[23] Q.P. Cao, Y. Ma, C. Wang, X.D. Wang, J.Z. Jiang. Effect of temperature and strain rate on deformation behavior in metallic glassy films, Thin Solid Films 561 (2014) 60-69.

[24] Y. Ma, Q.P. Cao, S.X. Qu, X.D. Wang, J.Z. Jiang. Effect of structural relaxation on plastic flow in a Ni-Nb metallic glassy film, Acta Mater 60 (2012) 3667-3676.

[25] [25] Y. Ma, Q.P. Cao, S.X. Qu, D.X. Zhang, X.D. Wang, J.Z. Jiang. Stress-state-dependent deformation behavior in Ni-Nb metallic glassy film, Acta Mater 60 (2012) 4136-4143.

[26] L. Yang, L. Lu. The influence of sample thickness on the tensile properties of pure Cu with different grain sizes, Scr Mater 69 (2013) 242-245.

[27] A.W. Goldenstein, W. Rostoker, F. Schossberger, G. Gutzeit. Structure of chemically deposited nickel, J Electrochem Soc 104 (1957) 104-110.

[28] R.M. Allen, J.B. VanderSande. The structure of electroless Ni-P films as a function of composition, Scr Metall 16 (1982) 1161-1164.

[29] R.J. Keyse, C. Hammond. Structure and morphology of electroless Ni-P deposits, Mater Sci Technol-lond 3 (1987) 963-972.

[30] G. Gutzeit. An outline of the chemistry involved in the process of catalytic nickel deposition from aqueous solution, Plating 46 (1959) 1158.

[31] C.C. Nee, R. Weil. The banded structure of Ni-P electrodeposits, Surface Technology 25 (1985) $7-15$.

[32] K. Ziewiec, P. Malczewski, G. Boczkal, K. Prusik. Formation and properties of amorphous/crystalline ductile composites in Ni-Ag-P immiscible alloys, Diffus. Defect Data B, Solid State Phenom. 186 (2012) 216-221.

[33] Y. Xiang, T. Li, Z.G. Suo, J.J. Vlassak. High ductility of a metal film adherent on a polymer substrate, Appl Phys Lett 87 (2005) 161910-161911.

[34] S. van Herwaarden, E. Iervolino, F. van Herwaarden, T. Wijffels, A. Leenaers, V. Mathot. Design, performance and analysis of thermal lag of the UFS1 twin-calorimeter chip for fast scanning calorimetry using the Mettler-Toledo Flash DSC 1, Thermochimica Acta 522 (2011) 46-52. 
[35] A. Donohue, F. Spaepen, R.G. Hoagland, A. Misra. Suppression of the shear band instability during plastic flow of nanometer-scale confined metallic glasses, Appl Phys Lett 91 (2007).

[36] N.S. Lu, Z.G. Suo, J.J. Vlassak. The effect of film thickness on the failure strain of polymer-supported metal films, Acta Mater 58 (2010) 1679-1687.

[37] N. Lu, X. Wang, Z. Suo, J. Vlassak. Metal films on polymer substrates stretched beyond 50\%, Appl Phys Lett 91 (2007) 221909-221903.

[38] T. Li, Z.Y. Huang, Z.C. Xi, S.P. Lacour, S. Wagner, Z. Suo. Delocalizing strain in a thin metal film on a polymer substrate, Mech Mater 37 (2005) 261-273.

[39] Z. Suo, L. Teng. Ductility of thin metal films on polymer substrates modulated by interfacial adhesion, Int J Solids Struct 44 (2007) 1696-1705.

[40] T.H. Fang, W.L. Li, N.R. Tao, K. Lu. Revealing extraordinary intrinsic tensile plasticity in gradient nano-grained copper, Science 331 (2011) 1587-1590.

[41] T. Li, Z. Suo. Deformability of thin metal films on elastomer substrates, Int J Solids Struct 43 (2006) 2351-2363.

[42] D.A. Hughes, N. Hansen. Microstructure and strength of nickel at large strains, Acta Mater 48 (2000) 2985-3004.

[43] H.J. Gao, B.H. Ji, I.L. Jager, E. Arzt, P. Fratzl. Materials become insensitive to flaws at nanoscale: Lessons from nature, Proc Natl Acad Sci 100 (2003) 5597-5600.

[44] Z.T. Wang, J. Pan, Y. Li, C.A. Schuh. Densification and strain hardening of a metallic glass under tension at room temperature, Phys Rev Lett 111 (2013) 135504.

[45] N. Boucharat, R. Hebert, H. Rosner, R. Valiev, G. Wilde. Nanocrystallization of amorphous $\mathrm{Al}_{88} \mathrm{Y}_{7} \mathrm{Fe}_{5}$ alloy induced by plastic deformation, Scr Mater 53 (2005) 823-828.

[46] N. Boucharat, R.J. Hebert, H. Roesner, G. Wilde. Deformation-induced nanocrystallization in Al-rich metallic glasses. in: Lojkowski W, Blizzard JR, (Eds.). Hight Pressure Technology of Nanomaterials, vol. 114. 2006. pp. 123-132.

[47] S. Pauly, S. Gorantla, G. Wang, U. Kuehn, J. Eckert. Transformation-mediated ductility in CuZr-based bulk metallic glasses, Nat Mater 9 (2010) 473-477.

[48] J. Pan, Q. Chen, L. Liu, Y. Li. Softening and dilatation in a single shear band, Acta Mater 59 (2011) 5146-5158.

[49] D. Deng, A.S. Argon. Structural relaxation and embrittlement of $\mathrm{Cu}_{59} \mathrm{Zr}_{41}$ and $\mathrm{Fe}_{80} \mathrm{~B}_{20}$ glasses, Acta Metall 34 (1986) 2011-2023.

\section{Figure captions}

Fig. 1. Cross-sectional SEM images of Ni-P amorphous film on coarse grained Ni substrate. Film thickness: (a) $26.4 \mu \mathrm{m}$ (b) $14.3 \mu \mathrm{m}$ (c) $10.5 \mu \mathrm{m}$ (d) $2.6 \mu \mathrm{m}$. Horizontal bandings are observed in (a) and (b).

Fig. 2. (a) Grazing incidence XRD patterns of surface amorphous film. (b) HRTEM images of the as-deposited Ni-P amorphous film. The inset shows the electron diffraction of the Ni-P film. 
Fig. 3. Tensile engineering stress-strain curves of four different thickness Ni-P films with Ni substrate. For comparison, the s-s curves of $\mathrm{Ni}$ substrate and $\mathrm{Ni}_{80} \mathrm{P}_{20}$ ribbon [30] are also included. The inset shows the sample geometries before and after tension.

Fig. 4. Surface SEM images of tensile samples after tensile tests. Film thickness: (a) $14.3 \mu \mathrm{m}$ (b) $10.5 \mu \mathrm{m}$ (c) $6.1 \mu \mathrm{m}$ (d) $2.6 \mu \mathrm{m}$. LA indicates the loading axis in tensile tests.

Fig. 5. Cross-sectional view (a) and plane view (b) of one half of the tensile sample with $14.3 \mu \mathrm{m}$ film after failure to illustrate the measurements of the thickness $(H)$ and width $(W)$ at corresponding positions. (c) The true strain calculated along the loading axis as a function of the distance from the arc ending.

Fig. 6. Snapshots of the local plastic strain distribution of the $14.3 \mu \mathrm{m} \mathrm{Ni-P}$ film surface detected by ARAMIS at engineering strain: (a) $5 \%$, (b) $25 \%$ (c) $25 \%$, CG Ni substrate without film.

Fig. 7. Magnified surface SEM images of tensile samples after tension. Film thickness: (a) $14.3 \mu \mathrm{m}$ (b) $10.5 \mu \mathrm{m}$ (c) $6.1 \mu \mathrm{m}$ (d) $2.6 \mu \mathrm{m}$. A few cracks induced by shear banding with angle of $\sim 45^{\circ}$ to depth direction are indicated by dashed circles. The tensile loading axis is aligned with the horizontal direction for all the images.

Fig. 8. Longitude-sectional SEM images of Ni-P film on $\mathrm{CG}$ Ni substrate at corresponding positions indicated by dash line in Fig.5a show that film thickness gradually variation with increasing tensile true strain. Thickness of the Ni-P film: (a) $26.4 \mu \mathrm{m}$ (b) $25.8 \mu \mathrm{m}$ (c) $25.6 \mu \mathrm{m}$; (d) $14.3 \mu \mathrm{m}$ (e) $11.4 \mu \mathrm{m}$ (f) $8.6 \mu \mathrm{m}$; (g) $2.6 \mu \mathrm{m}$ (h) $1.5 \mu \mathrm{m}$ (i) $0.8 \mu \mathrm{m}$.

Fig. 9. The film thickness reduction $T_{r}$ varied as a function of tensile true strain $\left(\varepsilon_{T}\right)$. 
Fig. 10. Variation of nanoindentation hardness on $14.3 \mu \mathrm{m} \mathrm{Ni-P}$ film with tensile true strain. (b-d) SEM images of the indentations at true strain of (b) $0 \%$, (c) $16 \%$, and (d) $96 \%$.

Fig. 11. (a) Flash DSC curves for various deformed $14.3 \mu \mathrm{m}$ Ni-P film. (b) The relaxation enthalpy of the deformed samples as a function of true strain in $14.3 \mu \mathrm{m}$ Ni-P film.

Fig. 12. The largest thickness reduction varied with the as-deposited film thickness.

Fig. 13. The applied stress $(\sigma)$ required for shear band (blue line) and crack (red line) propagation as a function of film thickness $(h)$. Here HF and SB represent homogeneous flow and shear banding, respectively. $h_{f}^{*}, h_{c f}^{*}, h_{c}^{*}$ means the critical film thickness for fully homogeneous flow, crack formation, maximum critical thickness for homogeneous flow, respectively. $h_{f}^{*}=184 \mathrm{~nm} . h_{c}^{*}=25 \mu \mathrm{m}$. The stresses in the films are estimated from the load differences between $\mathrm{Ni}-\mathrm{P} / \mathrm{Ni}$ and $\mathrm{Ni}$ in the uniform deformation stage on engineering stress-strain curves (Fig. 3). 

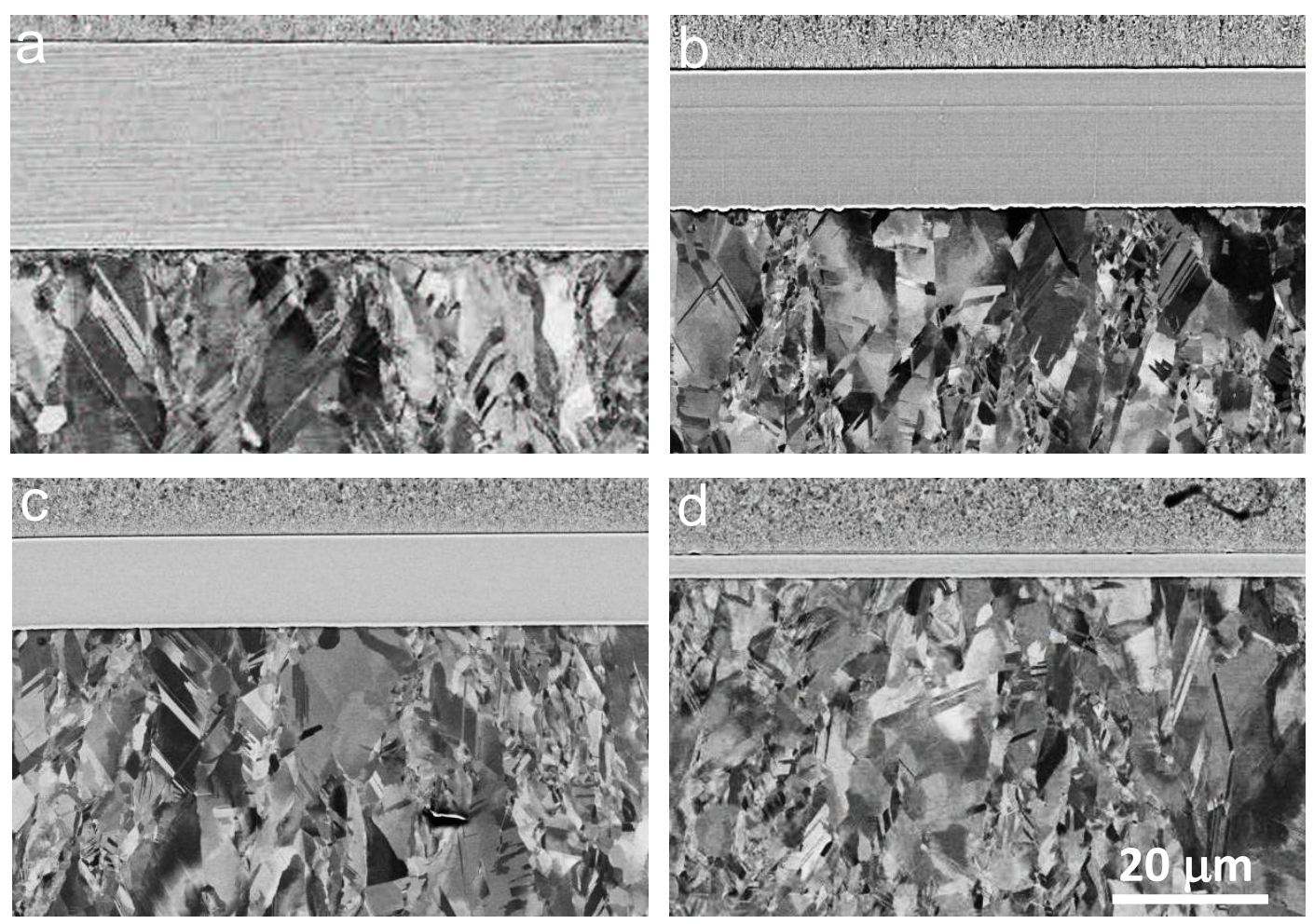

Figure 1/ Lu et al 

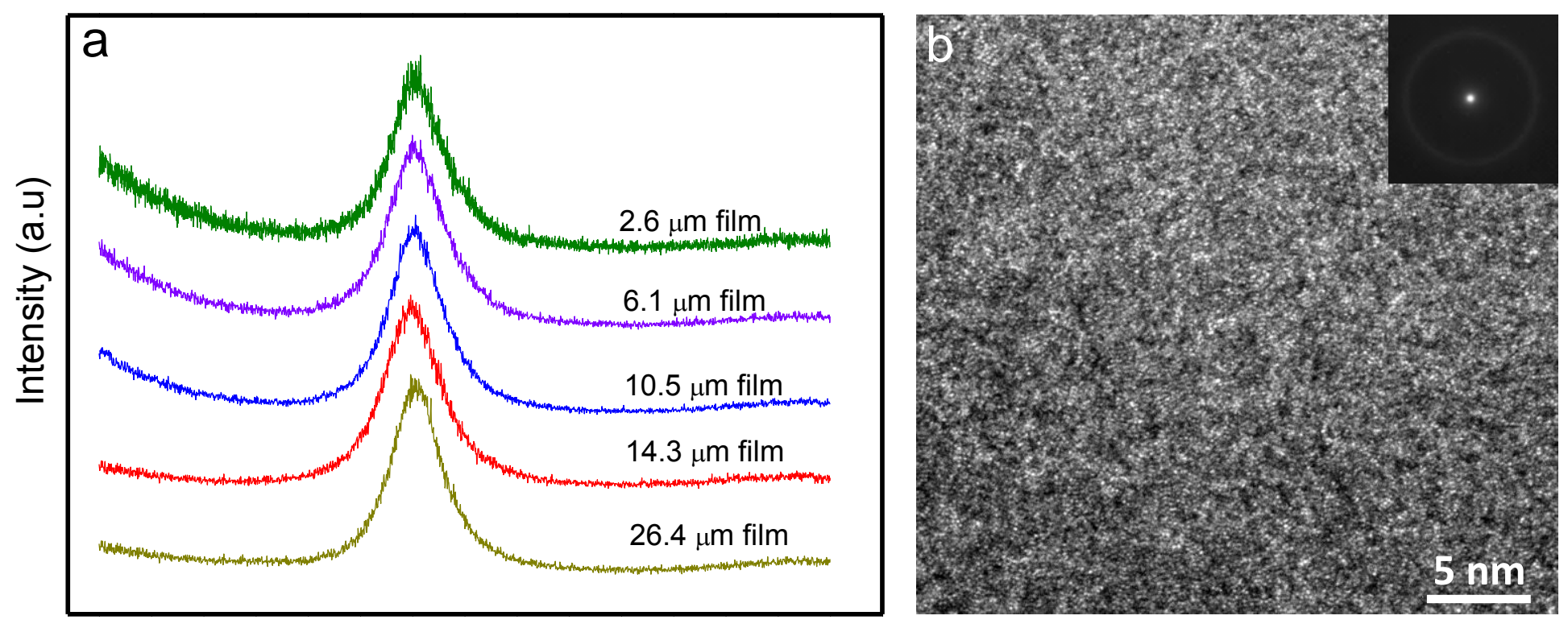

$2 \theta$ (degree)

Figure 2/ Lu et al 


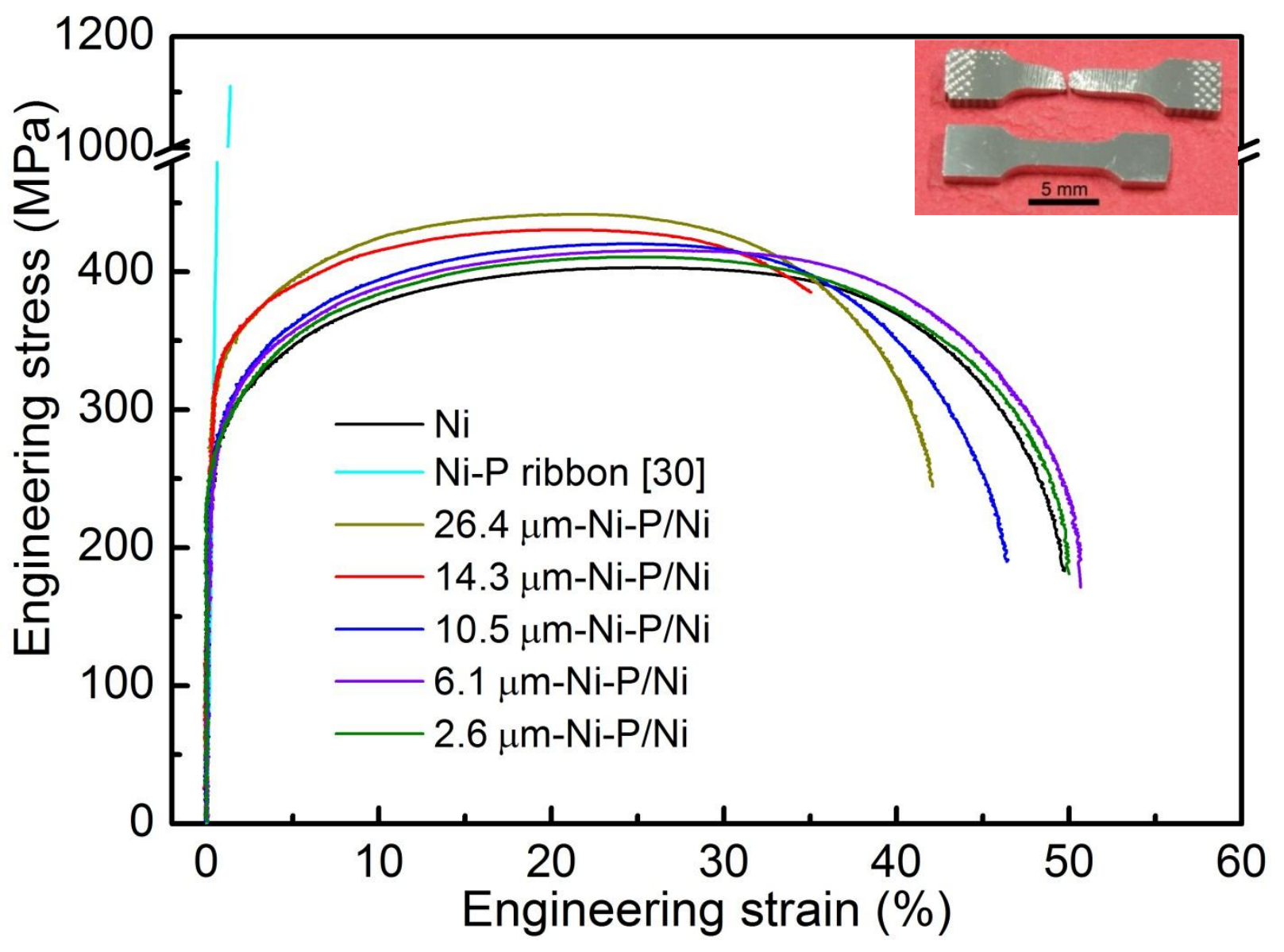

Figure 3/ Lu et al 

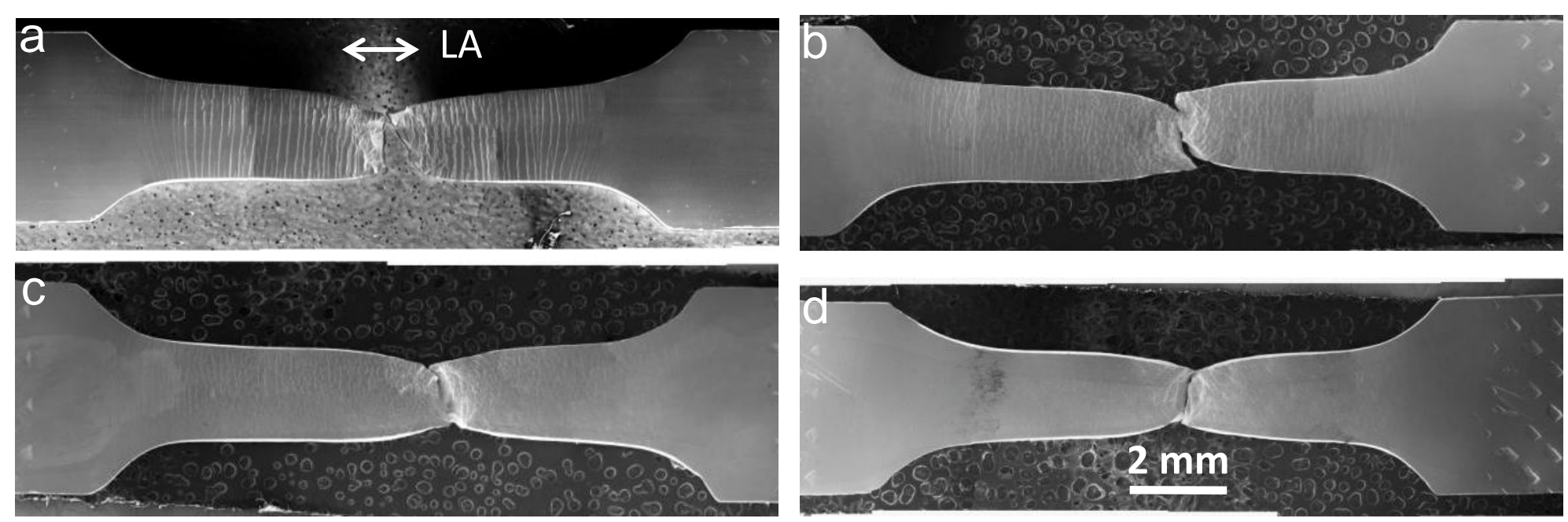

Figure 4/ Lu et al 


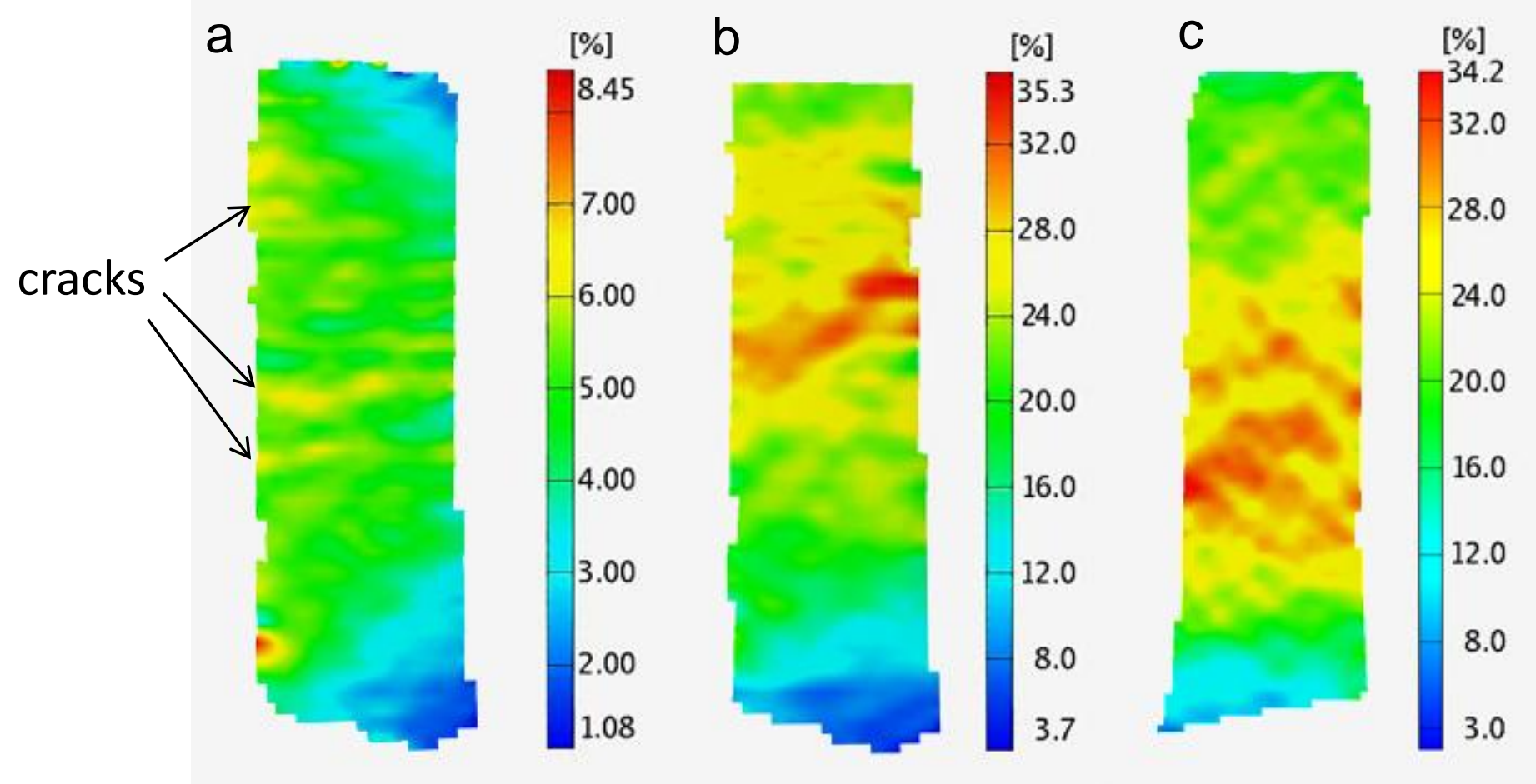

Figure 6/ Lu et al 


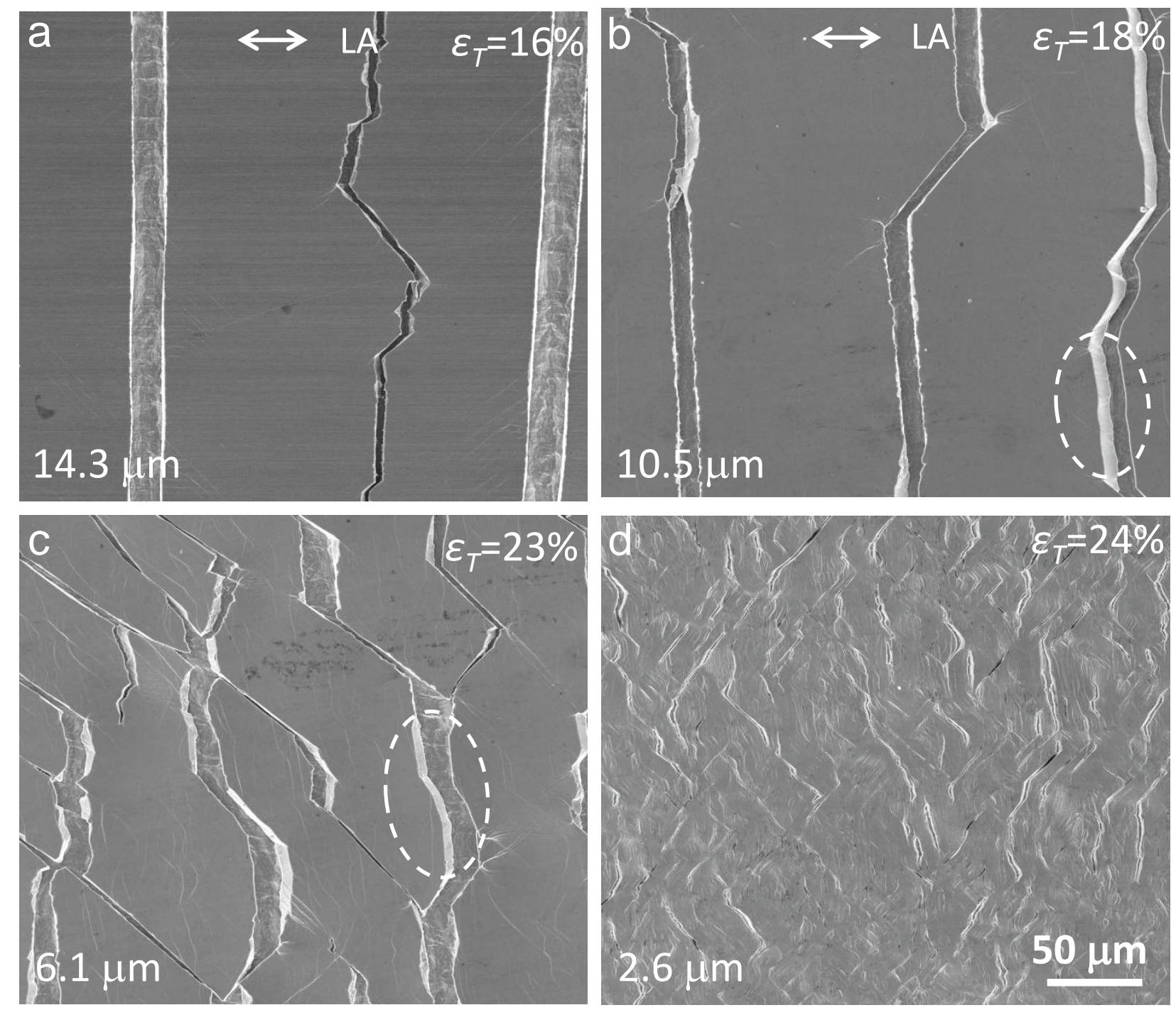

Figure 7 / Lu et al 


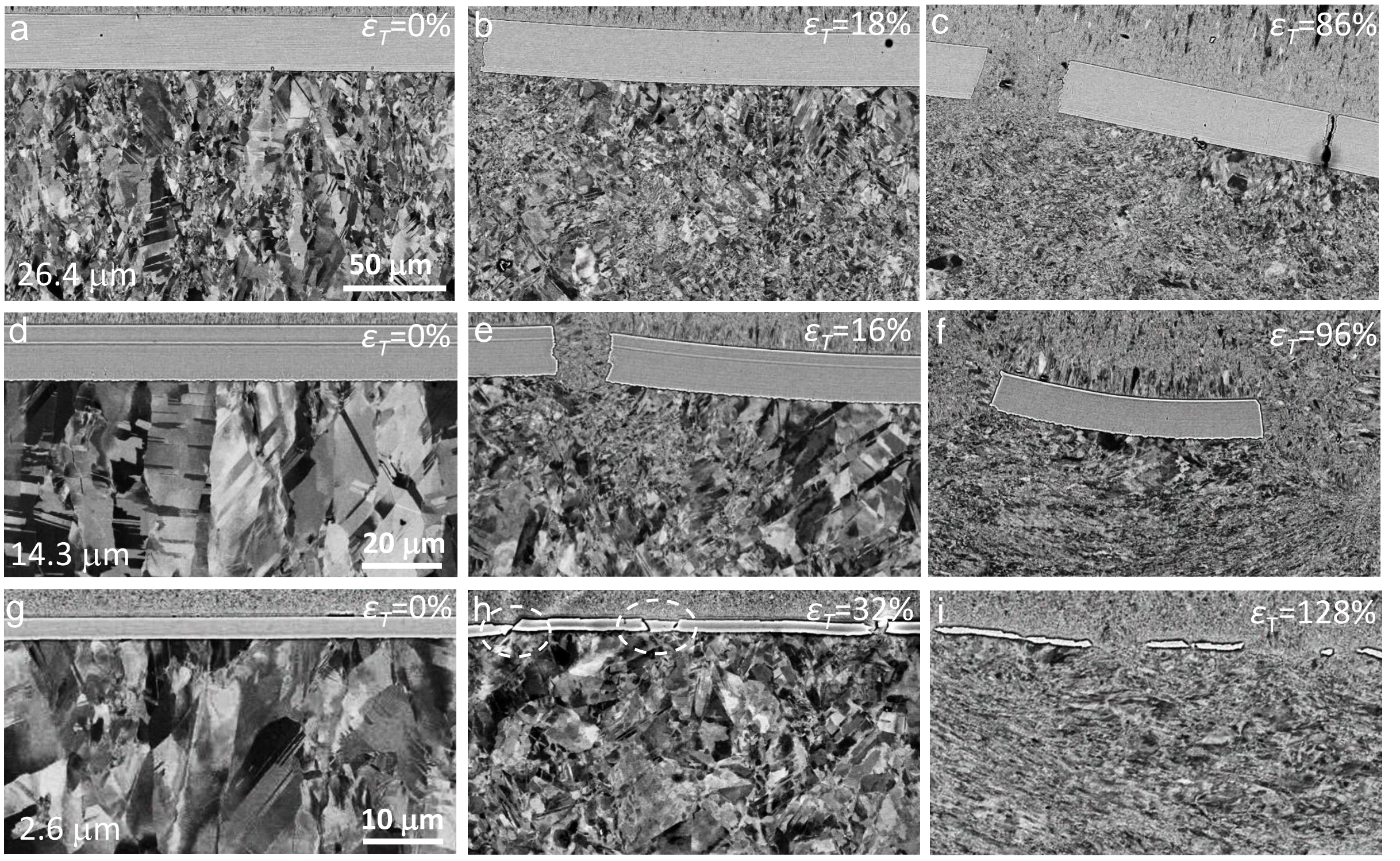

Figure 8/ Lu et al 


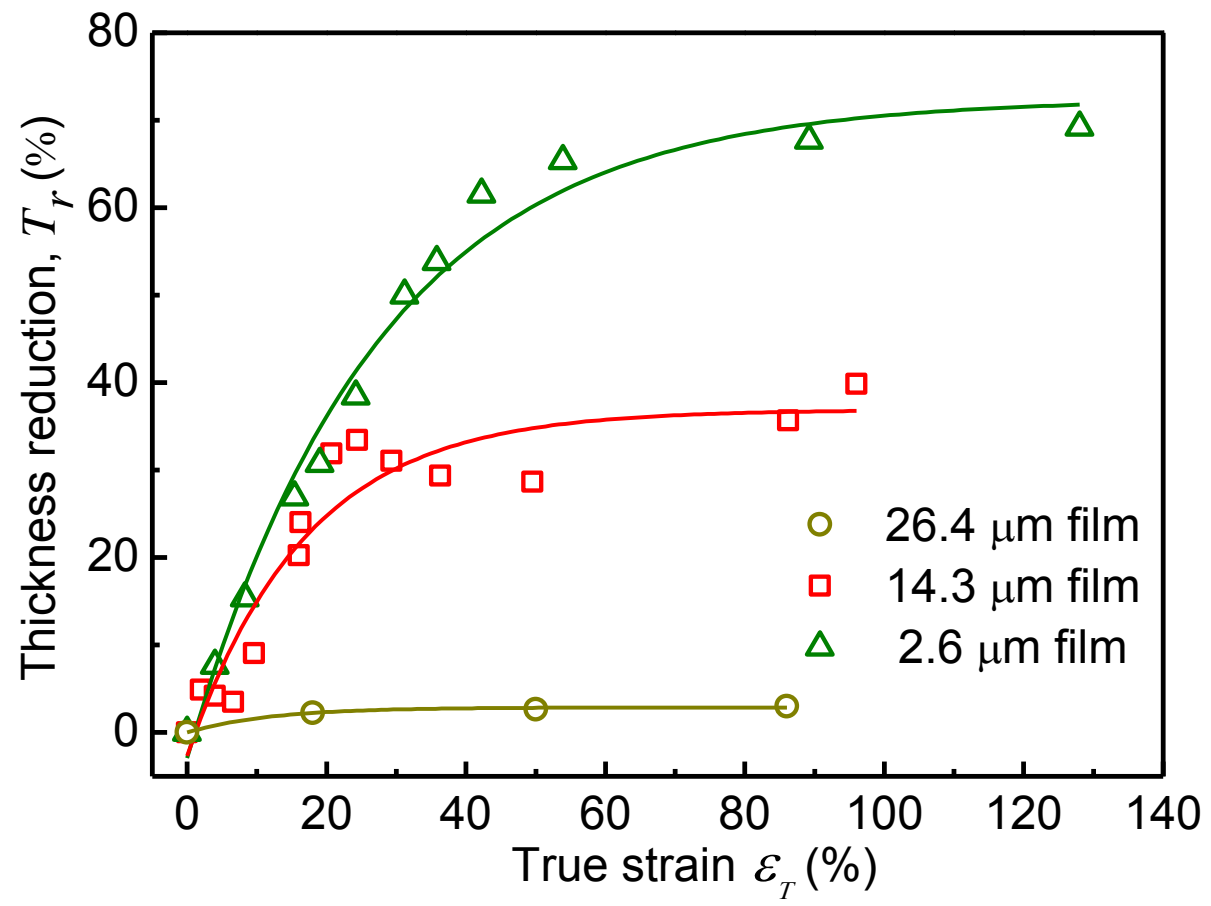

Figure 9/ Lu et al 


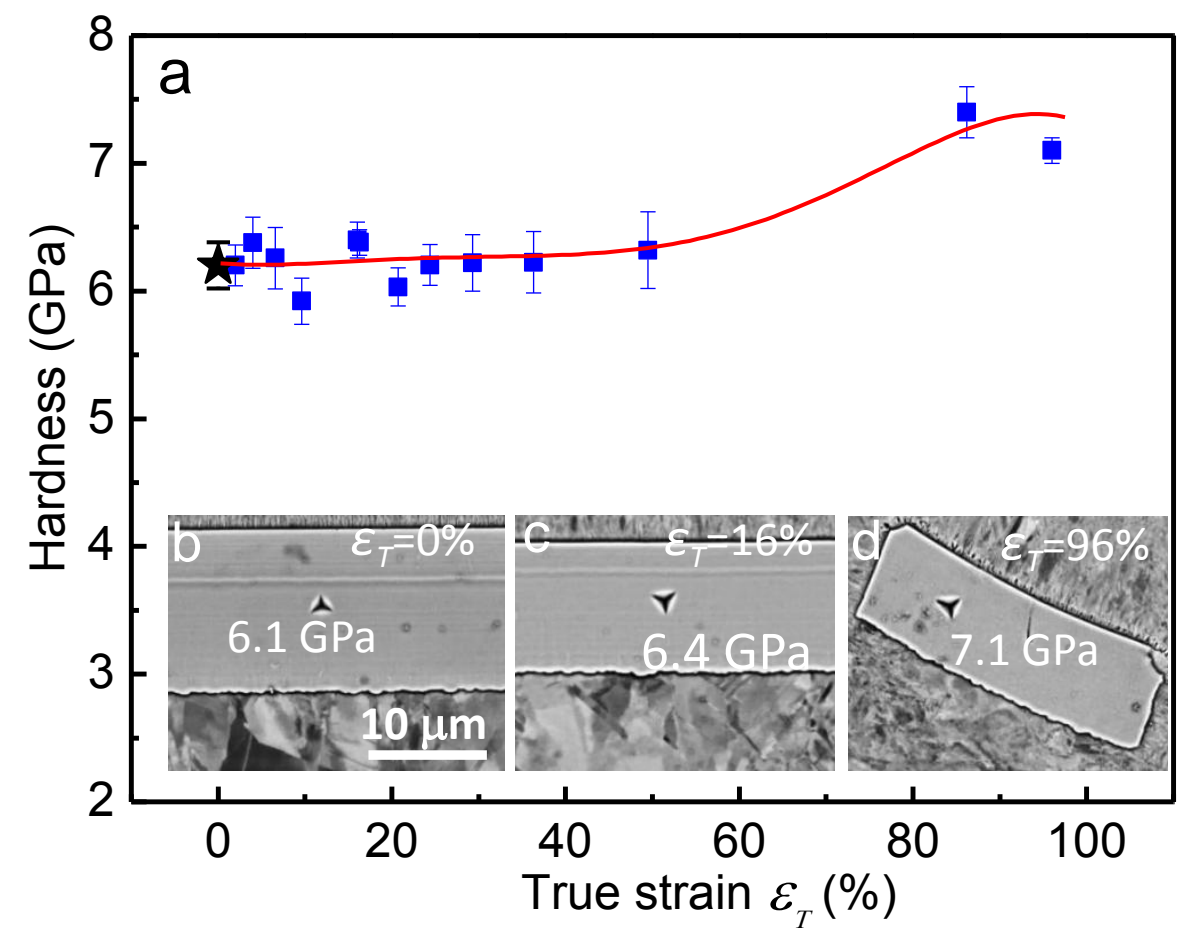

Figure 10/ Lu et al 

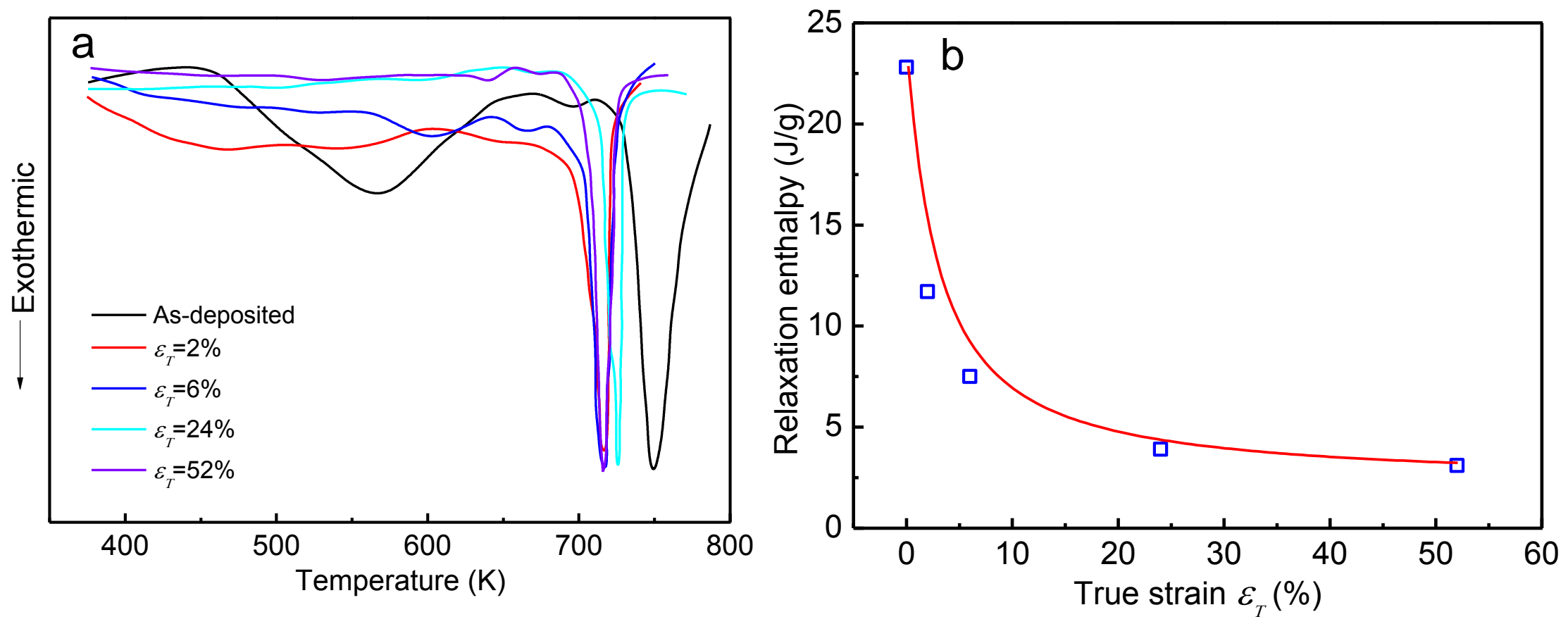

Figure 11/ Lu et al 


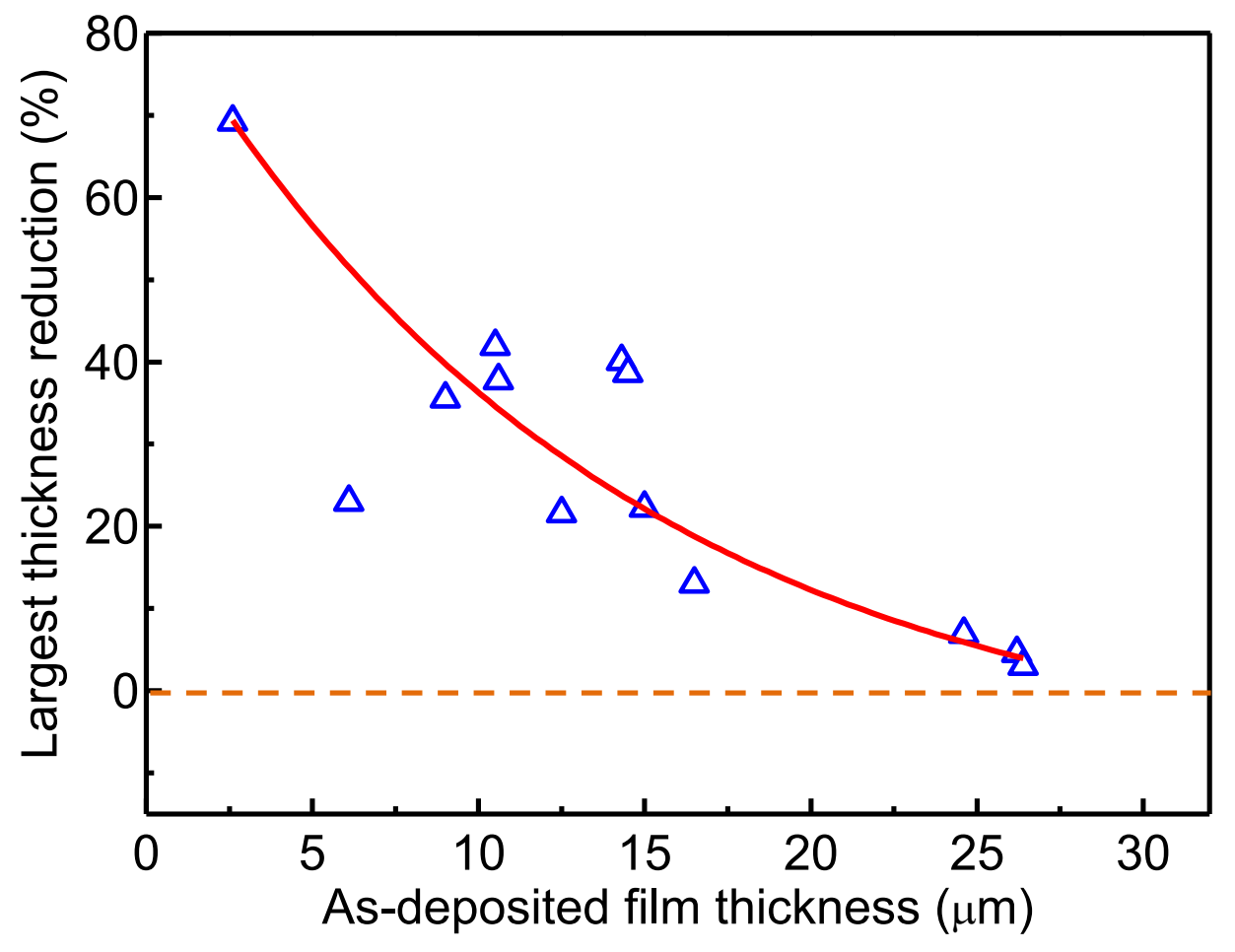

Figure 12/ Lu et al 


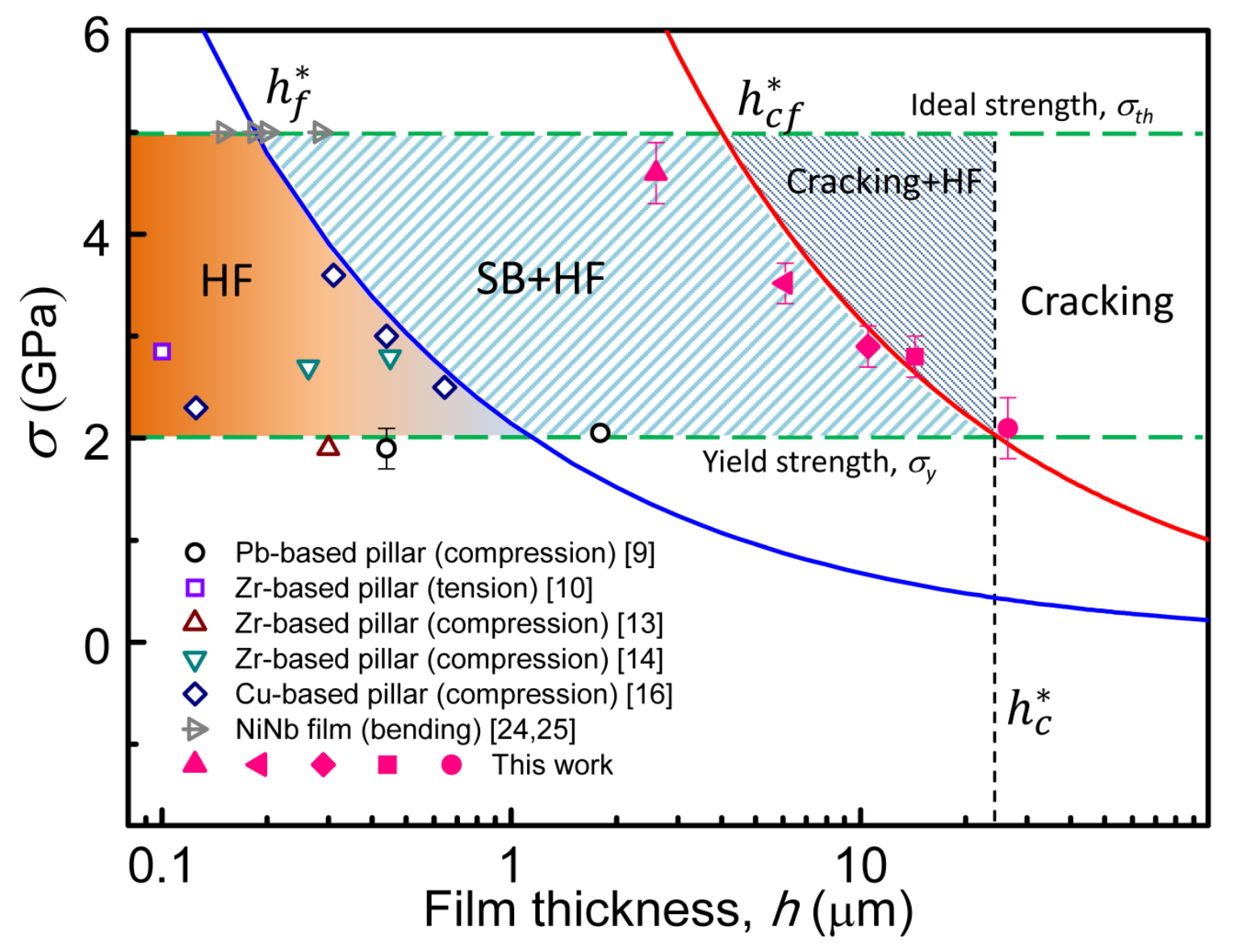

Figure 13/ Lu et al 
Table 1. Chemical compositions of Ni-P films with various thicknesses from EDX analysis.

\begin{tabular}{ccccc}
\hline Samples & $\begin{array}{c}\text { Film thickness } \\
(\mu \mathrm{m})\end{array}$ & $\begin{array}{c}\text { Substrate thickness } \\
(\mu \mathrm{m})\end{array}$ & $\begin{array}{c}\text { P weight } \\
(\%)\end{array}$ & $\begin{array}{c}\text { Ni weight } \\
(\%)\end{array}$ \\
\hline 1 & 26.4 & 1470 & 10.5 & 89.5 \\
2 & 14.3 & 1470 & 11.3 & 88.7 \\
3 & 10.5 & 1490 & 9.3 & 90.7 \\
4 & 6.1 & 1500 & 9.6 & 90.4 \\
5 & 2.6 & 1500 & 9.2 & 90.8 \\
\hline
\end{tabular}


A deformation map $(\sigma-h)$ is proposed to account for co-existence of homogeneous flow and localized plastic deformation (shear banding or cracking) in tension of metallic glassy Ni-P films on ductile substrate, as well as the gradual transition of deformation modes via the variation of film thickness.

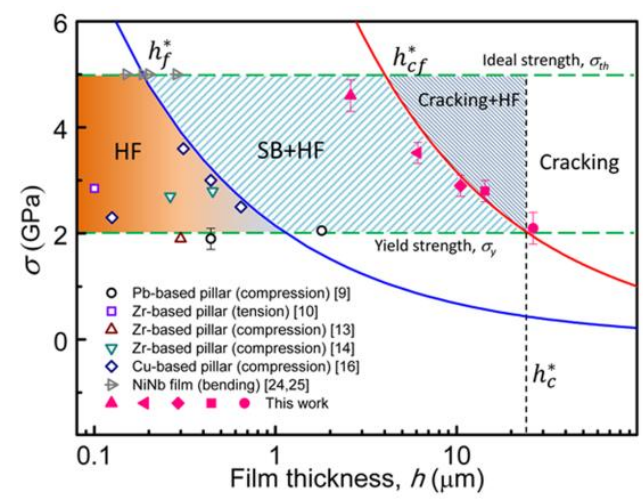

